INTUISI 12 (1) (2020)
INTUISI
JURNAL PSIKOLOGI ILMIAH
http://journal.unnes.ac.id/nju/index.php/INTUISI
Terindeks DOAJ: 2541-2965

\title{
CALLOUS UNEMOTIONAL TRAITS DAN PERUNDUNGAN MAYA PADA REMAJA (CALLOUS UNEMOTIONAL TRAITS AND CYBERBULLYING IN ADOLESCENTS)
}

\section{Aprilia Wira Sarifa ${ }^{\bowtie}$, Fatma Kusuma Mahanani}

Jurusan Psikologi, Fakultas Ilmu Pendidikan Universitas Negeri Semarang, Indonesia

\begin{tabular}{l}
\hline Info Artikel \\
\hline Sejarah Artikel: \\
Disubmit 9 Agustus 2019 \\
Direvisi 25 Maret 2020 \\
Diterima 30 Maret 2020 \\
\\
\hline Keywords: \\
Cyberbullying, Callous \\
Unemotional Traits, \\
Adolescents
\end{tabular}

\begin{abstract}
Abstrak
Perundungan maya menjadi masalah global yang terjadi salah satunya pada remaja. Faktor kepribadian menjadi salah satu penentu terjadinya hal tersebut, termasuk callous unemotional traits. Tujuan dalam penelitian ini untuk menjelaskan hubungan antara callous unemotional traits dan cyberbullying pada remaja di SMA Negeri Kota Semarang. Metode penelitian yang digunakan adalah penelitian korelasional. Penelitian ini dilakukan di 6 SMA Negeri Kota Semarang yang terpilih sebagai sampel. Responden berjumlah 188 remaja (usia 15-18 tahun). Penelitian ini menggunakan cluster random sampling. Skala cyberbullying terdiri dari 38 item dengan koefisien reliabilits 0,883. Skala callous unemotional traits terdiri dari 28 item dengan koefisien reliabilitas 0,894 . Uji hipotesis menggunakan teknik rank Spearman. Hasil analisis deskriptif menunjukkan bahwa cyberbullying pada 188 remaja di SMA Negeri Kota Semarang tergolong sangat rendah $(89,4 \%)$. Pada callous unemotional traits, callousness tergolong sangat rendah $(53,2 \%)$, uncaring tergolong sangat rendah $(65,4 \%)$ dan unemotional tergolong sedang $(52,1 \%)$. Berdasarkan hasil analisis inferensial diketahui bahwa callous unemotional traits dan cyberbullying memiliki hubungan yang signifikan sebesar $0,000(\mathrm{p}<0,05)$ dengan koefisien korelasi sebesar 0,469. Hal tersebut berarti bahwa semakin tinggi tingkat callous unemotional traits maka semakin tinggi pula tingkat cyberbullying pada remaja dan sebaliknya, semakin rendah callous unemotional traits maka akan rendah pula cyberbullying pada remaja.
\end{abstract}

\begin{abstract}
Cyberbullying is a global problem that occurs among adolescents. Personality factors become one of the determinants of this, including callous unemotional traits. The aim of the present study was to examine the association between callous unemotional traits and cyberbullying in adolescents in State Senior High School of Semarang City. The research methods used are correlational research. The present study held in six State Senior High School of Semarang City that chosen as the sample. Participants included 188 adolescents (aged 15-18). It used cluster random sampling. The cyberbullying scale included 38 items with coefficient reliability 0,883. Callous unemotional traits scale included 28 items with coefficient reliability 0,894. Hypothesis test in the present study used rank spearman. The descriptive analyses result showed cyberbullying in 188 adolescents at state senior high school of Semarang city was very low $(89,4 \%)$. On callous unemotional traits, callousness was very low $(53,2 \%)$, uncaring was very low $(65,4 \%)$ and unemotional was moderate $(52,1 \%)$. Based on inferential analyses result, callous unemotional traits and cyberbullying had significance of 0,000 ( $p<0,05)$ with coefficient correlation of 0,469. This means that the higher levels of callous unemotional traits, the higher levels of cyberbullying in adolescents and the lower levels of the callous unemotional traits, the lower levels of the cyberbullying in adolescents.
\end{abstract}

(C) 2020 Universitas Negeri Semarang

${ }^{凶}$ Alamat korespondensi:

Jurusan Psikologi, Fakultas Ilmu Pendidikan Universitas Negeri

p-ISSN 2086-0803

Semarang, Kampus Sekaran, Gunungpati, Semarang Indonesia

e-ISSN 2541-2965

apriliasarifa@gmail.com 


\section{PENDAHULUAN}

Laporan terbaru We Are Social, pada tahun 2020 (Haryanto, 2020) menunjukkan data pengguna internet di Indonesia mencapai 175,4 juta, yang artinya $64 \%$ dari penduduk Indonesia. Terdapat kenaikan $17 \%$ atau 25 juta pengguna internet pendidikan tahun 2019 . Usia pengguna internet berkisar antara 16 hingga 64 tahun. Laporan tersebut juga menyebutkan bahwa 160 juta warga Indonesia pengguna aktif media sosial (medsos) dengan peningkatan 10 juta pengguna endidikan tahun 2019.

\begin{tabular}{llr}
$\begin{array}{r}\text { Sosial } \\
\text { penggunanya }\end{array}$ & \multicolumn{1}{c}{ media } & $\begin{array}{r}\text { memudahkan } \\
\text { untuk }\end{array}$ \\
menyebarkan & informasikasi, & menambah
\end{tabular}
pertemanan dan berbagi konten secara mudah. Dibalik kelebihan yang diberikan sosial media memberikan dampak negatif, salah satunya adalah perundungan maya, yaitu tindakan mengirim atau mengunggah teks atau gambar berbahaya atau kejam menggunakan internet atau perangkat komunikasi digital lainnya (Willard, 2007).

Perundungan maya juga diartikan sebagai "tindakan agresif disengaja yang dilakukan oleh kelompok atau individu menggunakan media elektronik secara berulang kali terhadap korban yang tidak bisa membela dirinya sendiri" (Smith et al., 2008). Terdapat beberapa bentuk perundungan maya, diantaranya endidi, harasstment, denigration, impersonation, outing, trickery, exclusion, dan cyberstalking (Willard, 2007). Cyberbullying memiliki 3 aspek, yaitu intent to harm (keinginan untuk menyakiti orang lain), power imbalance (perbedaan kekuatan) dan repetition (pengulangan) (Smith, Tokunaga, \& Barrio, 2013).

Perundungan maya umumnya terjadi pada remaja (Cappadocia, Craig, \& Pepler, 2013). Batasan umur untuk tindakan perundungan maya adalah 18 tahun, sehingga apabila pelaku atau korban berusia lebih dari 18 tahun maka perbuatan tersebut termasuk dalam cybercrime (Priyatna, 2010). Selain itu, penelitian yang dilakukan pada remaja Australia diketahui bahwa cyberbullying dapat ditemukan pada remaja yang berusia 11 - 19 tahun (Campbell et al., 2013). Sejalan dengan hal tersebut, penelitian yang dilakukan di Inggris menyimpulkan bahwa perundungan maya masih jarang terjadi pada usia $12-13$ tahun (Fletcher et al., 2014), namun kecenderungan perundungan maya akan meningkat selama masa remaja (Hoff \& Mitchell, 2009).

Survey awal yang dilakukan oleh peneliti pada tahun 2019, yang dilakukan pada remaja terdiri dari 63 siswa SMA di Jawa Tengah, diperoleh data bahwa sebanyak 29 siswa $(46,03 \%)$ berada pada kategori rendah, 26 siswa $(41,27 \%)$ tergolong sedang dan 12 siswa $(19,05 \%)$ berada pada kategori perundungan maya yang tinggi. Penelitian sebelumnya yang dilakukan di SMA Negeri Kota Semarang, menunjukkan temuan satu siswa masuk kedalam kategori tinggi, 125 siswa sedang dan 354 siswa termasuk ke dalam perundungan maya rendah serta tidak ada perbedaan perilaku perundungan maya ditinjau dari jenis kelamin (Amelia, 2018).

Gambaran perundungan maya secara umum pada salah satu SMA dari jumlah total 286 subjek, terdapat 206 subjek berada pada kategori tinggi, 45 subjek berada pada kategori sedang dan 35 subjek berada pada kategori rendah. Pada SMA lainnya juga ditemukan kasus perundungan dengan jumlah yang tidak jauh beda yaitu sebanyak 235 siswa berada pada kategori tinggi, 71 siswa berada pada kategori sedang dan 30 siswa pada kategori rendah (Wirdaya, 2016).

Perundungan maya juga menyebabkan berbagai dampak negatif. Para korbannya merasa tak berdaya, kesedihan (Hoff \& Mitchell, 2009), depresi, merasa terisolasi, tidak memiliki teman, kurangnya support system, bahkan percobaan bunuh diri (Hinduja \& Patchin, 2010). Disamping itu perundungan maya juga memberikan dampak negatif pada pelakunya. Penelitian pada 
remaja Australia berusia $11-19$ tahun disimpulkan bahwa pelaku perundungan maya memiliki skor yang tinggi pada skala stress, depresi dan kecemasan serta skor kualitas hidup yang rendah (Fletcher et al., 2014).

Beberapa faktor internal berasal dari kepribadian dikaitkan dengan perundungan maya, diantaranya rasa iri, tidak adanya toleransi, dan persekongkolan untuk menolak seseorang dari suatu kelompok (Hoff \& Mitchell, 2009), rendahnya empati dan rendahnya harga diri (Brewer \& Kerslake, 2015). Selain itu endidi diri yang rendah dapat menjadi faktor yang revelan pada pelaku atau korban perundungan maya (Menesini \& Spiel, 2012). Penelitian lain menunjukkan pelaku perundungan maya memiliki kepercayaan diri yang rendah, harga diri yang rendah dan kesejahteraan psikologis yang buruk (Wong, Chan, \& Cheng, 2014). Faktor lain yang mempengaruhu perundungan maya adalah prundungan tradisional (Cappadocia, Craig, \& Pepler, 2013; Kim, et.al., 2018; Modecki, et.al., 2014; Satalina, 2014), persepsi terhadap korban (Satalina, 2014), strain (Hoff \& Mitchell, 2009) dan kepribadian (Festl \& Quandt, 2013).

Salah satu kepribadian yang mungkin berpengaruh terhadap perundungan maya adalah callous unemotional traits. Ditandai dengan rendahnya perasaan simpatik, tidak adanya penyesalan, tidak bertanggung jawab dengan kewajiban, tidak peduli dengan orang lain, dingin dan tidak peka terhadap orang lain (Byrd, Kahn, \& Pardini, 2013; Essau, Sasagawa, \& Frick, 2006; Fanti, Frick, \& Georgiou, 2009; Kimonis et al., 2008). Callous unemotional traits terdiri dari 3 aspek diantarnya callousness (kurangnya rasa bersalah), uncaring (tidak peduli terhadap orang lain) dan unemotional (dingin dan tidak peka terhadap orang lain) (Essau, Sasagawa, \& Frick, 2006).

Beberapa penelitian mengenai callous unemotional telah dilakukan, diantaranya oleh Ciucci, et al., (2014) untuk mengetahui hubungan callous unemotional traits dengan penyesuaian akademik dan perilaku pada siswa SMP. Fanti, Frick, \& Georgiou (2009) juga meneliti hubungan callous unemotional traits dan cyberbullying pada remaja di Yunani.

Dengan terbatasnya penelitian mengenai callous unemotional traits dan perundungan maya dan ramaja merupakan masa rentan terjadi banyak konflik, maka penelitian ini dirasa penting dengan tujuan untuk mengetahui gambaran callous unemotional traits dan perundungan maya pada Remaja SMA Negeri di Kota Semarang dan mengetahui hubungan antar kedua variabel tersebut. Manfaat penelitian ini adalah untuk memberikan kontribusi secara teoritis dan praktis terkait hubungan kedua variabel beserta gambarannya pada remaja untuk instansi endidikan maupun peneliti selanjutnya.

\section{METODE}

Penelitian ini merupakan penelitian korelasional. Varibel Penelitian ini adalah Callous Unemotional Traits dan Perundungan Maya. Variabel bebas dalam penelitian ini adalah Callous unemotional traits, yaitu suatu sifat pada seseorang yang membuat orang terkait tidak mampu berempati dengan baik, tidak merasa bersalah ketika melakukan hal menyimpang dan berekspresi datar (dingin) karena kurang mampu mengekspresikan emosi. Variabel ini akan diukur berdasarkan dimensi callous unemotional traits, yaitu callous, uncaring, dan unemotion. Sedangkan varibel tergantung, yaitu perundungan maya adalah segala bentuk hinaan, ejekan yang dilakukan oleh remaja maksimal berusia 18 tahun melalui media internet, khususnya sosial media dan adanya perbedaan kekuatan dengan pelaku memiliki kekuatan yang lebih tinggi daripada korban. Variabel ini akan diukur berdasarkan aspek perundungan maya diantaranya intent to harm, power imbalance dan repetition. Teknik sampling pada penelitian ini menggunakan cluster random sampling dengan mengambil 6 sekolah di SMA Negeri Kota Semarang. Jumlah 
sampel pada penelitian ini sebanyak 188 responden dengan rentan usia 15-18 tahun. Pengambilan data menggunakan dua skala, yaitu skala callous unemotional traits berjumlah 28 aitem dengan reliabilitas 0,894 dan skala perundungan maya berjumlah 38 aitem dengan reliabilitas 0,883 . Teknik analisis pada penelitian ini menggunakan rank Spearman.

\section{HASIL DAN PEMBAHASAN}

Responden merupakan remaja yang duduk di bangku SMA, sebagian besar berusia 17 tahun sebanyak $40 \%$, diikuti yang berusia 16 tahun sebanyak $34 \%$, lalu berusia 18 tahun sebanyak $15 \%$ dan berusia 15 tahun sebanyak $11 \%$. Responden pada penelitian ini sebagian besar duduk di kelas 11 atau sebanyak $41 \%$, selanjutnya kelas 10 sebanyak 33\% dan diikuti kelas 11 sebanyak 26\%, sebagian besar responden pada penelitian ini merupakan perempuan dengan presentase sebesar $66 \%$ dan sisanya laki-laki sebesar 34\%.

Berdasarkan hasil analisis deskriptif, hasil dari perundungan maya pada remaja di SMA Negeri Kota Semarang adalah 168 berada pada kategori sangat rendah, 18 pada kategori rendah, 1 pada kategori sedang, 1 pada kategori tinggi dan 0 pada kategori sangat tinggi.

Berikut adalah Tabel 1. Hasil Analisis Deskriptif Perundungan Maya.

Tabel 1

Hasil Analisis Deskriptif Perundungan Maya

\begin{tabular}{lcr}
\hline & & Perundungan Maya \\
\cline { 3 - 3 } \multicolumn{1}{c}{$\mathrm{N}$} & Valid & \multicolumn{1}{c}{188} \\
\cline { 2 - 3 } \multicolumn{1}{c}{ Missing } & \multicolumn{1}{c}{0} \\
\hline Mean & & 14.9574 \\
Median & & 12.0000 \\
Mode & & $14.00^{\mathrm{a}}$ \\
Std. Deviation & & 11.53040 \\
Variance & & 132.950 \\
Range & & 77.00 \\
Minimum & & .00 \\
Maximum & & 77.00 \\
Sum & & 2812.00 \\
Percentiles & 25 & 7.0000 \\
& 50 & 12.0000 \\
& 75 & 19.0000 \\
\hline
\end{tabular}

Sedangkan hasil pada callous unemotional traits secara umum berada pada kategori rendah 99 siswa $(52,7 \%)$. Ditinjau lebih dalam berdasarkan dimensinya, callousness secara umum berada pada kategori sangat rendah sebanyak 100 siswa $(53,2 \%)$, uncaring secara umum berada pada kategori sangat rendah sebanyak 123 siswa $(65,4 \%)$ dan unemotional secara umum berada pada kategori sedang sebanyak 98 siswa $(52,1 \%)$. Berikut adalah Tabel 2. Hasil Analisis Deskriptif Callous Unemotional Traits.

Tabel 2

Hasil Analisis Deskriptif Callous

Unemotional Traits

\begin{tabular}{lcr}
\hline \multirow{1}{*}{\multicolumn{1}{c}{$\mathrm{N}$}} & Valid & \multicolumn{1}{c}{ CU-TRAITS } \\
\cline { 2 - 3 } \cline { 3 - 3 } Mean & Missing & \multicolumn{1}{c}{0} \\
\hline Median & & 25.9362 \\
Mode & & 25.0000 \\
Std. Deviation & & $24.00^{\mathrm{a}}$ \\
Variance & & 9.89226 \\
Range & & 97.857 \\
Minimum & & 56.00 \\
Maximum & & 4.00 \\
Sum & & 60.00 \\
Percentiles & 25 & 4876.00 \\
& 50 & 20.0000 \\
& 75 & 25.0000 \\
\end{tabular}

Sebelum melakukan uji hipotesis, dilakukan uji asumsi berupa uji normalitas dan linieritas. Hasil uji normalitas menunjukan bahwa callousness, uncaring dan unemotional memiliki sebaran data yang normal dengan masing-masing signifikansi sebesar $0.023,0.015$ dan 0.024 ( $p>0.01$ ). Namun sebaliknya, sebaran data perundungan maya berdistribusi tidak normal karena signifikansi 0.000 atau $\mathrm{p}<0.01$.

Berdasarkan uji linieritas diketahui nilai $\mathrm{p}$ sebesar 0.000 hal ini berarti $\mathrm{p}<0.05$ yang menunjukkan antara callousness dan perundungan maya adalah linier, uncaring dan perundungan maya menghasilkan $\mathrm{p}$ sebesar 0.000 yang berarti kedua data linier, antara 
unemotional dan perundungan juga dikatakan linier dengan $\mathrm{p}$ sebesar $0.000(\mathrm{p}<0.05)$.

Dalam penelitian ini, analisis data dilakukan teknik korelasi rank Spearman. Teknik ini digunakan untuk mengetahui tingkat hubungan antar variabel yaitu callous unemotional traits dan perundungan maya ketika sebaran datanya tidak normal (non parametrik).

Callous unemotional traits dan perundungan maya memiliki signifikansi 0,000 dan koefisien korelasi sebesar 0,469. Hal ini berarti $\mathrm{p}<0,05$ sehingga ada hubungan positif antara callous unemotional traits dan perundungan maya pada 188 remaja di SMA Negeri Kota Semarang.

Penelitian ini juga memaparkan korelasi masing-masing dimensi callous unemotional traits dengan perundungan maya. Koefisien korelasi antara callousness dan perundungan maya sebesar 0.480 . Nilai signifikansinya sebesar $0.000 \quad(\mathrm{p}<0.05)$, koefisien korelasi antara uncaring dan perundungan maya sebesar 0.364 dan nilai signifikansi sebesar $0.000(\mathrm{p}<0.05)$, koefisien korelasi antara unemotional dan perundungan maya sebesar 0.264 dengan signifikansi sebesar $0.000(\mathrm{p}<0.05)$. Hal ini menunjukkan ada hubungan positif yang signifikan antara masing-masing aspek callous unemotional traits dan perundungan maya.

Penelitian ini menghasilkan beberapa temuan bahwa terdapat hubungan yang positif signifikan antara callous unemotional traits dan perundungan maya. Masing-masing dimensi callous unemotional traits juga memiliki hubungan yang positif signifikan, baik callousness, uncaring, maupun unemotional dikaitkan dengan perundungan maya.

Temuan secara umum, responden memiliki tingkat perundungan maya pada kategori sangat rendah, dan callous unemotional traits kategori secara umum pada kategori rendah Jika dilihat per dimensi, callousness berada pada kategori sangat rendah, uncaring berada pada kategori sangat rendah dan unemotional berada pada kategori sedang cenderung tinggi. Berdasar ketiga dimensi tersebut, dapat disimpulkan bahwa perundungan maya yang dilakukan responden cenderung lebih banyak berorelasi poistif dengan unemotional.

$$
\text { Temuan pada responden }
$$
menunjukkan perundungan maya yang sangat rendah yang dapat dianalisis terjadi karena pengalaman perundungan tradisional yang rendah. Hal ini sejalan dengan penelitian yang dilakukan oleh Modecki et al. (2014) bahwa antara perundungan tradisional dan perundungan maya memiliki korelasi yang kuat. Selain itu kepribadian juga mempengaruhi perundungan maya yang berbeda-beda, salah satunya adanya kepribadian ekstrovert (Festl \& Quandt, 2013; Satalina, 2014). Keluarga merupakan protektif yang dapat mengurangi seorang remaja terlibat dalam perundungan maya (Davis \& Koepke, 2016; Fanti, Demetriou, \& Hawa, 2012).

Callous unemotional traits secara umum berada pada kategori rendah. Menurut Waller \& Hyde (2017) bahwa callous unemotional traits cenderung dipengaruhi oleh bagaimana peran orang tua dalam mendidik anak. Kehangatan dalam pengasuhan yang diberikan orang tua kepada anaknya akan akan membuat callous unemotional traits yang rendah. Selain itu faktor genetik dan jenis kelamin juga dapat mempengaruhi callous unemotional. Perempuan cenderung memiliki skor callous unemotional yang lebih rendah daripada lakilaki (Moore et al., 2017; Viding \& Mccrory, 2012).

Hubungan positif signifikan antara callous unemotional traits dan perundungan maya pada penelitian ini sejalan dengan hasil penelitian longlitudinal yang dilakukan oleh Fanti, Demetriou, \& Hawa (2012) bahwa callous unemotional traits berhubungan dengan perundungan maya. Pada penelitian 
yang dilakukan Kimonis, et al. (2014) menemukan bahwa anak-anak dengan masalah perilaku yang tinggi memiliki skor callous unemotional traits yang tinggi pula. Anak-anak dengan masalah perilaku sedang menunjukkan skor callous unemotional traits yang sedang pula.

$$
\text { Callous unemotional traits }
$$

berhubungan dengan perundungan maya dikarenakan pelaku cenderung memiliki empati yang rendah (Brewer \& Kerslake, 2015) dan callous unemotional traits dicirikan dengan rendahnya perasaan empati. Longman et al. (2016) mengatakan bahwa adanya disfungsi amigdala dan keterlambatan pematangan kortikal di daerah yang terlibat dalam pengambilan keputusan, moralitas. dan empati. Hal ini menyebabkan ketika callous unemotional traits tinggi maka perasaan empati rendah (Muñoz, Qualter, \& Padgett, 2011).

Cyberbullying merupakan perilaku agresif dan callous unemotional traits memprediksi pola-pola dari perilaku agresi (Fanti, Frick, \& Georgiou, 2009). Callousness dan uncaring pada callous unemotional traits berhubungan positif dengan bullying, masalah perilaku, dan perilaku agresif (Ciucci et al., 2014). Anak-anak dan remaja yang memiliki skor tinggi pada callous unemotional traits mereka cenderung kurang peka terhadap rasa takut dan perasaan orang lain. Mereka juga lebih mudah melakukan agresi dan akan cenderung mem-bully orang lain. Mereka dicirikan memiliki callous unemotional traits yang tinggi (Zych et al., 2016; Fanti, Frick, \& Georgiou, 2009).

Psikopat merupakan salah satu faktor yang memprediksi adanya bullying dan callous unemotional traits merupakan faktor resiko dari psikopat. Callous unemotional traits merupakan salah satu faktor risiko dari perilaku antisosial dan psikopat (Essau, Sasagawa, \& Frick, 2006; Frick et al., 2014). Uncaring berhubungan dengan defisit emosional dan callousness dan uncaring berhubungan dengan agresi dimana keduanya merupakan sifat-sifat psikopat (Essau, Sasagawa, \& Frick, 2006; Henry et al., 2016; Fanti, Frick, \& Georgiou, 2009). Goodboy \& Martin (2015) melakukan penelitian untuk mencari tahu hubungan antara perundungan maya dan dark triad, hal ini diperoleh bahwa turunan dari dark triad yaitu psikopat merupakan faktor prediktor dari perundungan maya. Hal ini sejalan dengan Van et al. (2017) bahwa remaja yang memiliki sifat psikopat maka cenderung memiliki skor tinggi pada perilaku perundungan.

Hubungan antara anak dan orang tuamenjadi penting dalam perkembangan callous unemotional traits dan terlibatnya perundungan. Remaja yang sering terlibat perundungan memiliki hubungan dengan keluarga yang tidak suportif, misalnya, pola asuh dan pengawasan orang tua yang buruk (Davis \& Koepke, 2016; Pepler et al., 2008; Waller \& Hyde, 2017). Meskipun pengasuhan dari orang tua tidak memiliki pengaruh langsung dengan berkembangnya callous unemotional traits, tetapi terhadap tempramen anak.

\section{SIMPULAN}

Dari pemaparan diatas dapat disimpulkan bahwa 1) cyberbullying pada 188 remaja di SMA Negeri Kota Semarang berada pada kategori sangat rendah, 2) aspek callous unemotional traits pada 188 remaja di SMA Negeri Kota Semarang berada pada kategori berbeda-beda, callousness berada pada kategori sangat rendah, uncaring berada pada kategori sangat rendah dan unemotional berada pada kategori sedang, 3) terdapat hubungan positif yang signifikan antara tiap aspek callous unemotional traits dan cyberbullying pada remaja di SMA Negeri Kota Semarang.

Peneliti mengajukan saran sebagai berikut, 1) Saran bagi sekolah diharapkan dapat membuat program preventif untuk meningkatkan empati guna mencegah 
tingginya skor callous unemotional traits yang nantinya akan menyebabkan timbulnya masalah perilaku atau cyberbullying, 2) Bagi peneliti selanjutnya, jika ada peneliti yang tertarik untuk melakukan penelitian eksperimen, hal ini dapat menjadi dasar untuk dapat menurunkan skor unemotional dengan lebih memperdalam bagaimana treatment yang sesuai untuk menurunkan unemotional, 3) Peneliti selanjutnya juga diharapkan dapat membandingkan alat ukur yang sudah ada sebelumnya dan menambah jumlah sampel agar lebih representatif.

\section{DAFTAR PUSTAKA}

Amelia, E. (2018). Cyberbullying Ditinjau Dari Jenis Kelamin (Penelitian pada Siswa SMA Negeri Kota Semarang). Universitas Negeri Semarang, Semarang.

Brewer, G., \& Kerslake, J. (2015). Cyberbullying, self-esteem, empathy and loneliness. Computers in Human Behavior, 48, 255-260. doi:10.1016/j.chb.2015.01.073

Byrd, A. L., Kahn, R. E., \& Pardini, D. A. (2013). A validation of the inventory of callous-unemotional traits in a community sample of young adult males. Journal of Psychopathology and Behavioral Assessment, 35(1), 20-34. doi:10.1007/s10862-012-9315-4

Campbell, M. A., Slee, P. T., Spears, B., Butler, D., \& Kift, S. (2013). Do cyberbullies suffertoo? Cyberbullies' perceptions of the harm they cause to others and to their own mental health. School Psychology International, 34, 613-629.

doi: $10.1177 / 0143034313479698$

Cappadocia, M. C., Craig, W. M., \& Pepler, D. (2013). Cyberbullying. Canadian Journal of School Psychology, 28(2), 171-192. doi: $10.1177 / 0829573513491212$

Ciucci, E., Baroncelli, A., Franchi, M., Golmaryami, F. N., \& Frick, P. J.
(2014). The association between callousunemotional traits and behavioral and academic adjustment in children: Further validation of the inventory of callousunemotional traits. Journal of Psychopathology and Behavioral Assessment, 36(2), 189-200. doi:10.1007/s10862-013-9384-z

Davis, K., \& Koepke, L. (2016). Risk and protective factors associated with cyberbullying: Are relationships or rules more protective? Learning, Media and Technology, 41(4), 521-545. doi:10.1080/17439884.2014.994219

Essau, C. A., Sasagawa, S., \& Frick, P. J. (2006). Callous-unemotional traits in a community sample of adolescents. Assessment, 13(4), 454-469. doi:10.1177/1073191106287354

Fanti, K. A., Demetriou, A. G., \& Hawa, V. V. (2012). A longitudinal study of cyberbullying: Examining riskand protective factors. European Journal of Developmental Psychology, 9(2), 168181.

doi:10.1080/17405629.2011.643169

Fanti, K. A., Frick, P. J., \& Georgiou, S. (2009). Linking callous-unemotional traits to instrumental and noninstrumental forms of aggression. Journal of Psychopathology and Behavioral Assessment, 31(4), 285-298. doi:10.1007/s10862-008-9111-3

Festl, R., \& Quandt, T. (2013). Social Relations and Cyberbullying: The Influence of Individual and Structural Attributes on Victimization and Perpetration via the Internet. Human Communication Research, 39(1), 101126. doi:10.1111/j.14682958.2012.01442.x

Fletcher, A., Fitzgerald-Yau, N., Jones, R., Allen, E., Viner, R. M., \& Bonell, C. (2014). Brief report: Cyberbullying perpetration and its associations with socio-demographics, aggressive behaviour at school, and mental health 
outcomes. Journal of Adolescence, 37(8), 1393-1398. doi:10.1016/j.adolescence.2014.10.005

Frick, P J, Ray, J. V, Thornton, L. C., \& Kahn, R. E. (2014). Can callousunemotional traits enhance the understanding, diagnosis, and treatment of serious conduct problems in children and adolescents? A comprehensive review. Psychological Bulletin, 140(1), 1-57. doi:10.1037/a0033076

Frick, Paul J., Ray, J. V., Thornton, L. C., \& Kahn, R. E. (2014). Annual research review: A developmental psychopathology approach to understanding callous-unemotional traits in children and adolescents with serious conduct problems. Journal of Child Psychology and Psychiatry and Allied Disciplines, 55(6), 532-548. doi:10.1111/jcpp.12152

Goodboy, A. K., \& Martin, M. M. (2015). The personality profile of a cyberbully: Examining the Dark Triad. Computers in Human Behavior, 49, 1-4. doi:10.1016/j.chb.2015.02.052

Henry, J., Pingault, J. B., Boivin, M., Rijsdijk, F., \& Viding, E. (2016). Genetic and environmental aetiology of the dimensions of Callous-Unemotional traits. Psychological Medicine, 46(2), 405-414. doi:10.1017/S0033291715001919

Haryanto, A.T. (2020). Riset: Ada 175,2 Juta Pengguna Internet di Indonesia, diakses 23 maret 2020 pada https://inet.detik.com/cyberlife/d4907674/riset-ada-1752-juta-penggunainternet-di-indonesia

Hinduja, S. \& Patchin, J. W. (2010). Bullying, Cyberbullying, and Suicide. Archives of Suicide Research, 14(3), 206-221

Hoff, D. L., \& Mitchell, S. N. (2009). Cyberbullying: causes, effects, and remedies. Journal of Educational Administration, 47(5), 652-665. https://doi.org/10.1108/09578230910981 107

Kim, S., Colwell, S. R., Kata, A., Boyle, M. H., \& Georgiades, K. (2018). Cyberbullying Victimization and Adolescent Mental Health: Evidence of Differential Effects by Sex and Mental Health Problem Type. Journal of Youth and Adolescence, 47(3), 661-672. doi:10.1007/s 10964-017-0678-4

Kimonis, E. R., Fanti, K. A., \& Singh, J. P. (2014). Establishing Cut-off Scores for the Parent-Reported Inventory of Callous-Unemotional Traits. Archives of Forensic Psychology, 1(1), 27-48.

Kimonis, E. R., Frick, P. J., Skeem, J. L., Marsee, M. A., Cruise, K., Munoz, L. C., ... Morris, A. S. (2008). Assessing callous-unemotional traits in adolescent offenders: Validation of the Inventory of Callous-Unemotional Traits. International Journal of Law and Psychiatry, 31(3), 241-252. doi:10.1016/j.ijlp.2008.04.002

Longman, T., Hawes, D. J., \& Kohlhoff, J. (2016). Callous-Unemotional Traits as Markers for Conduct Problem Severity in Early Childhood: A Meta-analysis. Child Psychiatry and Human Development, 47(2), 326-334. doi:10.1007/s10578-015-0564-9

Menesini, E., \& Spiel, C. (2012). Introduction: Cyberbullying: Development, consequences, risk and protective factors. European Journal of Developmental Psychology, 9(2):163167

Modecki, K. L., Minchin, J., Harbaugh, A. G., Guerra, N. G., \& Runions, K. C. (2014). Bullying prevalence across contexts: A meta-analysis measuring cyber and traditional bullying. Journal of Adolescent Health, 55(5), 602-611. doi:10.1016/j.jadohealth.2014.06.007

Moore, A. A., Carney, D., Moroney, E., Machlin, L., Towbin, K. E., Brotman, 
M. A., ... Hettema, J. M. (2017). The Inventory of Callous-Unemotional Traits (ICU) in Children: Reliability and Heritability. Behavior Genetics, 47(2), 141-151. doi:10.1007/s10519-016-98311

Muñoz, L. C., Qualter, P., \& Padgett, G. (2011). Empathy and bullying: Exploring the influence of callousunemotional traits. Child Psychiatry and Human Development, 42(2), 183-196. doi:10.1007/s10578-010-0206-1

Pepler, D., Jiang, D., Craig, W., \& Connolly, J. (2008). Developmental trajectories of bullying and associated factors. Child Development, $\quad 79(2), \quad 325-338$. doi:10.1111/j.1467-8624.2007.01128.x

Priyatna, A. (2010). Let's End Bullying: Memahami, Mencegah \& Mengatasi Bullying. Jakarta: Gramedia.

Satalina, D. (2014). Kecenderungan Perilaku Cyberbullying Ditinjau Dari Tipe Kepribadian Ekstrovert dan Introvert. Jurnal Ilmiah Psikologi Terapan, 2(2), 294-310.

Smith, P. K., Mahdavi, J., Carvalho, M., Fisher, S., Russell, S., \& Tippett, N. (2008). Cyberbullying: Its nature and impact in secondary school pupils. Journal of Child Psychology and Psychiatry and Allied Disciplines. doi:10.1111/j.1469-7610.2007.01846.x

Smith, P. K., Tokunaga, R., \& Barrio, C. del. (2013). Definitions of bullying and cyberbullying: How useful are the terms? In Principles of Cyberbullying Research: Definitions, Measures, and Mergodology (pp. 26-40).
Van G. M., Toprak, F., Goemans, A., Zwaanswijk, W., \& Vedder, P. (2017). Are Youth Psychopathic Traits Related to Bullying? Meta-analyses on CallousUnemotional Traits, Narcissism, and Impulsivity. Child Psychiatry and Human Development, 48(5), 768-777. doi:10.1007/s10578-016-0701-0

Viding, E., \& Mccrory, E. J. (2012). Genetic and neurocognitive contributions to the development of psychopathy. Development and Psychopathology, 24(3), 969-983. doi:10.1017/S095457941200048X

Waller, R., \& Hyde, L. W. (2017). CallousUnemotional Behaviors in Early Childhood: Measurement, Meaning, and the Influence of Parenting. Child Development Perspectives, O(0), 1-7. doi:10.1111/cdep.12222

Willard, N. (2007). Educator's Guide to Cyberbullying and Cyberthreats.

Wirdaya, O. A. (2016). Cyberbullying pada Remaja Pengguna Jejaring Sosial. Semarang: Psikologi Universitas Negeri Semarang.

Wong, D. S. W., Chan, H. C. O., \& Cheng, C. H. K. (2014). Cyberbullying perpetration and victimization among adolescents in Hong Kong. Children and Youth Services Review, 36(1), 133-140

Zych, I., Ttofi, M. M., \& Farrington, D. P. (2016). Empathy and CallousUnemotional Traits in Different Bullying Roles. Trauma, Violence, \& Abuse, l(19), $\quad 152483801668345$. doi:10.1177/1524838016683456 